\title{
Noise and Bandwidth Consideration in Designing Op-Amp Based Transimpedance Amplifier for VLC
}

\author{
Trio Adiono, Rachmad Vidya Wicaksana Putra, Syifaul Fuada \\ University Center of Excellence on Microelectronics, Institut Teknologi Bandung \\ IC Design laboratory, PAU Building 4th floor, ITB Campus, Jln. Tamansari No.126, Bandung (40132), Indonesia
}

\section{Article Info \\ Article history: \\ Received Dec 05, 2017 \\ Revised May 06, 2018 \\ Accepted May 20, 2018 \\ Keywords: \\ Noise and bandwidth analysis Transimpedance amplifier Visible Light Communication (VLC)}

\begin{abstract}
In a visible light communication (VLC) system, there are many modules involved. One of the important modules is Transimpedance Amplifier (TIA) that resides in the analog front-end receiver (Rx-AFE). TIA is responsible for performing signal conversion from current signal, which is provided from the photodiode (PD) to voltage signal. It is the reason why the TIA should be operating in low noise condition and wide bandwidth of frequency. These will enable a flexible coverage of the VLC system in performing its signal processing. Hence, in this research, we provide considerations of the noise and frequency bandwidth analysis in designing TIA to cope with the required design specification of a VLC system.
\end{abstract}

Copyright () 2018 Institute of Advanced Engineering and Science. All rights reserved.

\section{Corresponding Author:}

Syifaul Fuada,

University Center of Excellence on Microelectronics,

Institut Teknologi Bandung,

IC Design laboratory, PAU Building 4th floor, ITB Campus,

Jln. Tamansari No.126, Bandung (40132), Indonesia

Email: syifaulfuada@pme.itb.ac.id

\section{INTRODUCTION}

Visible Light Communication (VLC) is an alternative method for wireless communication besides radio frequency (RF) based communication. It uses visible light with the wavelength ranging from $380 \mathrm{~nm}-$ $780 \mathrm{~nm}$ as communication medium [1]. VLC also has several advantages compared to RF and infrared (IR), such as high-speed communication and robustness against electromagnetic interference [2]. Moreover, it is considered to be efficient and safe for daily implementation [3]. Nowadays, VLC becomes a popular topic to investigate because of its potential and future vision of applications. Many kinds of research have been conducted to enable this optical wireless communication technology. There are several interesting topics which are extensively discussed, such as:

a. Modulation scheme: Pulse Width Modulation [4]-[7], Pulse Position Modulation [8], Binary Phase-shift Keying [9-10], Quadrature Phase-shift Keying [11], Quadrature Amplitude Modulation [12] and etc;

b. Analog front-end (AFE) design: AFE circuit [13]-[14], analog filter circuits [15]-[16], automatic gain controller design [17]-[19], LED driver design [20]-[24], TIA [25], and etc.;

c. VLC's noise investigation: [26]-[28];

d. Digital signal processing (DSP): DSP prototyping [29], Viterbi encoder [30]-[31], system-on-chip (SoC) [32-33], and etc.;

e. Simulation model [34];

f. The applications: robotics [35], transportation [36], medical devices [37], audio transmission system [3839], light fidelity [40-41] and etc.

g. Security issues [42]; 
Moreover, VLC technology rises with the support of Light Emitting Diode (LED) technology development because LED can be switched in high speed which is required for VLC implementation. The use of LED for VLC has other benefits that can be achieved as well, such as better efficiency and longer lifetime than standard neon or light bulb. Hence, VLC technology is very interesting topic to investigate.

In a VLC system, there are many modules involved. One of them is Transimpedance Amplifier (TIA) which resides in the receiver (Rx). TIA is used to convert current signal produced by a photodiode (PD), to voltage signal. In order to make it works properly, TIA should operate in low noise condition and wide bandwidth of frequency. These conditions enable a flexible coverage and functionalities of the following signal processing in VLC system. Hence, in this paper, we observe the considerations in designing TIA in terms of noise and frequency bandwidth analysis to full fill the specification of a VLC system. Hopefully, it can give a picture of what to consider in designing Operational Amplifier (Op-Amp) based TIA for VLC system in terms of noise and bandwidth issues.

This paper is presented in several sections. The first one is the introduction, the second one is general VLC system and the third one is related theories on noise and bandwidth analysis. The noise and bandwidth analysis are presented in the fourth section along with case study. It will be followed and enclosed by concluding remarks and references, respectively.

\section{RELATED THEORIES}

The general circuit of Op-Amp based TIA is depicted in Figure 2. From literature, we can find that the noise analysis on Transimpedance Amplifier (TIA) is extensively studied. In summary, there are three main sources of noise in TIA, they are input current noise, input voltage noise and the feedback resistor thermal noise [43-44]. The main equations of the noise from input current, input voltage and feedback resistor thermal are presented in Equation 1, Equation 2 and Equation 3 respectively.

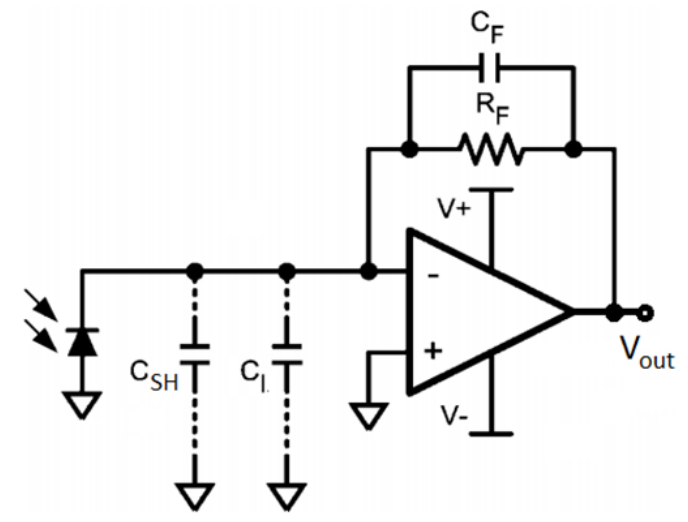

Figure 2. The general circuit of Op-Amp based TIA for VLC

$$
\begin{aligned}
& N_{\text {current }}=I_{n} R_{f} \sqrt{\mathrm{ENBW}} \\
& N_{\text {voltage }}=N_{2} \sqrt{\frac{\pi}{2} f_{p 2}} \\
& N_{R_{f}}=\sqrt{4 k T R_{f} \mathrm{ENBW}}
\end{aligned}
$$

The noise from input current $\left(N_{\text {current }}\right)$ is defined to be a result of multiplication among Op-Amp current noise density $\left(I_{n}\right)$, feedback resistor $\left(R_{f}\right)$ and the square root of equivalent noise bandwidth (ENBW). We can observe that $N_{\text {current }}$ is proportional with the value of all mentioned parameters. The definition of ENBW is given in Equation 4 and it is proportional to the $-3 \mathrm{~dB}$ frequency. The $-3 \mathrm{~dB}$ frequency itself is a function formed by gain bandwidth product frequency $\left(f_{G B P}\right)$, feedback resistor $\left(R_{f}\right)$ and total capacitor $\left(C_{T}\right)$, which can be stated as Equation 5 for clear formulation. Here, the definition of the total capacitor is total capacitance emerged from photodiode $\left(C_{s h}\right)$ and input of Op-Amp $\left(C_{i}\right)$ as stated in Equation 6. 


$$
\begin{aligned}
& \mathrm{ENBW}=f_{-3 d B} \frac{\pi}{2} \\
& f_{-3 d B}=\sqrt{\frac{f_{G B P}}{2 \pi R_{f} C_{T}}} \\
& C_{T}=C_{i}+C_{s h}
\end{aligned}
$$

The noise from input voltage $\left(N_{\text {voltage }}\right)$ is defined to be a result of multiplication among plateau noise $\left(N_{2}\right)$ and square root of second pole $\left(f_{p 2}\right)$ times $\pi / 2$. With the assumptions that the first pole and zero of the output noise density is minimum a decade lower than the second pole, thus the output noise is equal to the plateau noise [43]. The equation of $N_{2}$ is presented in Equation 7. It includes the voltage noise density $\left(e_{n}\right)$, Op-Amp input capacitance $C_{i}$, shunt capacitor from photodiode $C_{s h}$ and the feedback capacitor $C_{f}$, as the function variables. In other hand, the $f_{p 2}$ is constructed by $f_{G B P}, C_{i}, C_{s h}$ and $C_{f}$ as presented in Equation 8.

The feedback capacitor $C_{f}$ is placed across $R_{f}$ to create a pole at $f_{p}$ in noise gain function in order to maintain the stability [39] as illustrated in Figure 3. This placement definition of feedback capacitor $C_{f}$ can be stated as Equation 9.

$$
\begin{aligned}
& N_{2}=e_{n}\left(\frac{C_{i}+C_{s h}+C_{f}}{C_{f}}\right) \\
& f_{p 2}=f_{G B P}\left(\frac{C_{f}}{C_{i}+C_{s h}+C_{f}}\right)
\end{aligned}
$$

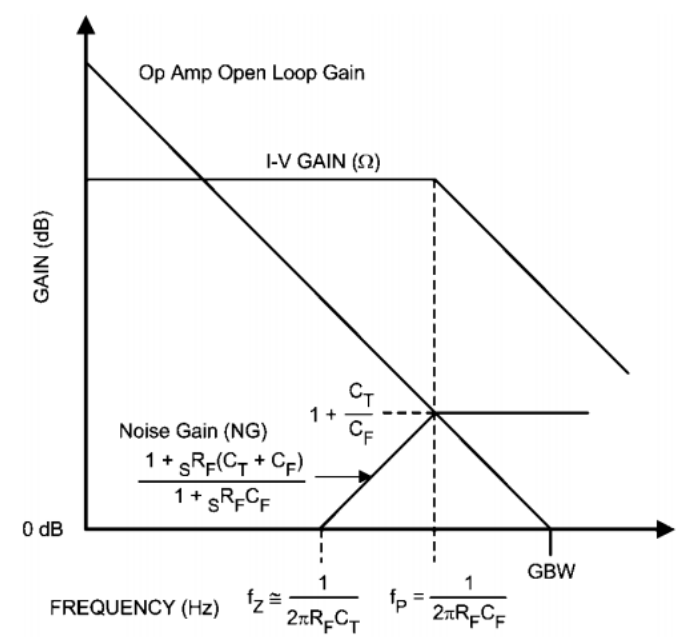

Figure 3. The bode plot graph of intersection between noise gain with Op-Amp open-loop gain [45]

$$
C_{f}=\sqrt{\frac{C_{T}}{2 \pi R_{f} f_{G B P}}}=\sqrt{\frac{C_{i}+C_{s h}}{2 \pi R_{f} f_{G B P}}}
$$

Last one is the noise from feedback resistor $\left(N_{R f}\right)$. It is defined by square root of multiplication among the Boltzmann constant $(k)$, temperature in Kelvin $(T), R_{f}$, ENBW and value of 4 . We have described 
the definition ENBW, thus we can obtain the result faster using the previously calculated value of ENBW. All noise values from three noise sources have been obtained, thus we can calculate the total noise $\left(N_{\text {total }}\right)$ occurred in the TIA circuit. Since, these three noise sources are independents, the total noise is the root-sumsquare (RSS) from all of noise sources as stated in Equation 10. A low pass filter (LPF) on the output of TIA is beneficial to reduce the $N_{\text {total }}$ if $f_{p 2}$ is much higher than the signal bandwidth $f_{G B P}$ [45].

$$
N_{\text {total }}=\sqrt{N_{\text {current }}^{2}+N_{\text {voltage }}^{2}+N_{R_{f}}^{2}}
$$

\section{THE ANALYSIS AND CASE STUDY}

\subsection{Mathematical Analysis}

From the third section, we see that there is a mathematical relation between noise and bandwidth frequency in designing TIA. Firstly, if we observe in input current noise $N_{\text {current }}$, we can derive Equation 11 from the existing equations. Noise of input current is mathematically proportional to the gain bandwidth product frequency $\left(f_{G B P}\right)$. Hence, if we want to cover a wider bandwidth $f_{G B P}$, it could end up with the increasing of the input current noise $N_{\text {current }}$. Basically, the value of $R_{f}$ and $C_{T}$ can be chosen, so that the $R_{f}$ is low and $C_{T}$ is high to minimize the input current noise $N_{\text {current }}$. But of course, the selection of $R_{f}$ and $C_{T}$ depends on the capability of the chosen Op-Amp and its corresponding characteristics.

$$
\begin{aligned}
N_{\text {current }} & =I_{n} R_{f}\left(f_{-3 d B} \frac{\pi}{2}\right)^{\frac{1}{2}} \\
& =I_{n} R_{f}\left(\left(\frac{f_{G B P}}{2 \pi R_{f} C_{T}}\right)^{\frac{1}{2}} \frac{\pi}{2}\right)^{\frac{1}{2}} \\
& =I_{n}\left(\frac{\pi f_{G B P} R_{f}^{3}}{8\left(C_{i}+C_{s h}\right)}\right)^{\frac{1}{4}}
\end{aligned}
$$

Secondly, if we observe the input voltage noise $N_{\text {voltage }}$, we can derive Equation 12 from the existing equations. The input voltage noise $N_{\text {voltage }}$ is proportional to the gain bandwidth product frequency $f_{G B P}$. This manner is just like the $N_{\text {current }}$. Hence, if we want to cover wider bandwidth $f_{G B P}$, the input voltage noise $N_{\text {voltage }}$ could end up to be higher as well. The interesting part is that the total capacitance $C_{T}$ is proportional to the input voltage noise $N_{\text {voltage. }}$ This manner is different with $N_{\text {current }}$. Thus, these conditions need to be strategically compensated and could be a trade-off for Op-Amp devices selection. 


$$
\begin{aligned}
& N_{\text {voltage }}=e_{n}\left(\frac{C_{i}+C_{s h}+C_{f}}{C_{f}}\right)\left(\frac{\pi}{2} f_{G B P}\left(\frac{C_{f}}{C_{i}+C_{s h}+C_{f}}\right)\right)^{\frac{1}{2}} \\
& =e_{n}\left(\frac{\pi}{2} f_{G B P}\left(\frac{C_{i}+C_{s h}+C_{f}}{C_{f}}\right)\right)^{\frac{1}{2}} \\
& =e_{n}\left(\frac{\pi}{2} f_{G B P}\left(\frac{C_{i}+C_{s h}+\left(\frac{C_{i}+C_{s h}}{2 \pi R_{f} f_{G B P}}\right)^{\frac{1}{2}}}{\left(\frac{C_{i}+C_{s h}}{2 \pi R_{f} f_{G B P}}\right)^{\frac{1}{2}}}\right)\right)^{\frac{1}{2}} \\
& =e_{n}\left(\frac{\pi}{2} f_{G B P}\left(\frac{C_{i}+C_{s h}}{\left(\frac{C_{i}+C_{s h}}{2 \pi R_{f} f_{G B P}}\right)^{\frac{1}{2}}}+1\right)\right)^{\frac{1}{2}} \\
& =e_{n}\left(\left[\frac{\pi^{3}}{2} R_{f} f_{G B P}^{3}\left(C_{i}+C_{s h}\right)\right]^{\frac{1}{2}}+\frac{\pi}{2} f_{G B P}\right)^{\frac{1}{2}}
\end{aligned}
$$

Lastly, if we observe the equation of feedback resistor noise $N_{R f}$, we can extract this equation as presented in Equation 13. Position of the gain bandwidth product frequency $\left(f_{G B P}\right)$ is proportional to the feedback resistor noise $N_{R f}$. Basically, the value of $R_{f}$ and $C_{T}$ could be chosen, thus the $R_{f}$ is low and $C_{T}$ is high in order to minimize the $N_{R f}$. It is similar with the idea in the $N_{\text {current }}$ section.

$$
\begin{aligned}
N_{R_{f}} & =\left(4 k T R_{f} f_{-3 d B} \frac{\pi}{2}\right)^{\frac{1}{2}} \\
& =\left(4 k T R_{f}\left(\frac{f_{G B P}}{2 \pi R_{f} C_{T}}\right)^{\frac{1}{2}} \frac{\pi}{2}\right)^{\frac{1}{2}} \\
& =\left(4 k T R_{f}\left(\frac{f_{G B P}}{2 \pi R_{f}\left(C_{i}+C_{s h}\right)}\right)^{\frac{1}{2}} \frac{\pi}{2}\right)^{\frac{1}{2}} \\
& =\left(k T\left(\frac{2 \pi f_{G B P} R_{f}}{C_{i}+C_{s h}}\right)^{\frac{1}{2}}\right)^{\frac{1}{2}}
\end{aligned}
$$

These mathematical analysis lead to the main idea on low noise design of input current noise $N_{\text {current }}$, input voltage noise $N_{\text {voltage }}$ and feedback resistor $N_{R f}$. In the first case, the $N_{\text {current }}$ is synchronous and convergent with $N_{R f}$, because the $R_{f}$ needs to be designed as low as possible and the $C_{T}$ as high as possible for obtaining low noise design. Meanwhile in case of $N_{\text {voltage }}$, a bit contrary manner emerges, because both of the $R_{f}$ and $C_{T}$ need to be designed as low as possible. Besides, other important thing that we also need to consider is the selection of $R_{f}$ and $C_{T}$ depends on the operational characteristics of the Op-Amp device itself. 


\subsection{Case Study: Profiling Op-Amps for VLC TIA}

In this sub-section, we investigate two kinds of Op-Amp for case study on designing TIA circuit for VLC system. Here, we use Op-Amp OPA656 and AD8011AN and give various condition of bandwidth as free variables in order to find the noise response. Other variables are designed to remain controlled in particular value as presented in Table I. The selection of values for these parameters depends on the datasheet for Op-Amp operational characteristics. Results of these experiments are presented in Figure 4 - Figure 7 as graphs.

Table 1. Op-Amps Parameters

\begin{tabular}{cccccc}
\hline Op-Amp & $R_{f}(\Omega)$ & $\begin{array}{c}C_{s h} \\
(\text { Farad })\end{array}$ & $\begin{array}{c}C_{i} \\
(\text { Farad })\end{array}$ & $\begin{array}{c}e_{n} \\
(\mathrm{~V} / \sqrt{\mathrm{Hz}})\end{array}$ & $I_{n}(\mathrm{~A} / \sqrt{\mathrm{Hz}})$ \\
\hline OPA-656 & $47 \times 10^{3}$ & $3.5 \times 10^{-12}$ & $3.4 \times 10^{-12}$ & $7 \times 10^{-9}$ & $1.3 \times 10^{-15}$ \\
AD8011AN & $47 \times 10^{3}$ & $3.5 \times 10^{-12}$ & $2.3 \times 10^{-12}$ & $2 \times 10^{-9}$ & $5.0 \times 10^{-12}$ \\
\hline
\end{tabular}

Figure 4 is a graph of input current noise $N_{\text {current }}$ vs gain bandwidth product frequency $f_{G B P}$. We can see that noise performance for Op-Amp OPA656 is lower than AD8011AN. It shows that the current noise density $I_{n}$ holds a dominant role in determining the $N_{\text {current }}$ here, $R_{f}$ is proportional and $C_{T}$ is disproportional. It is a bit contrary to the input voltage noise $N_{\text {voltage }}$ in Figure 5. In this case, value of $N_{\text {voltage }}$ is affected proportionally by the value of $R_{f}, C_{T}$ and $e_{n}$. It is supported by Table I in which the capacitor and noise density values are higher in OPA656 than AD8011AN. Meanwhile, the feedback resistor noises $N_{R f}$ between these Op-Amps are close to each other as proven in Figure 6. If we trace the equations, we see that the difference between these two Op-Amps is only on capacitor value. A slight difference in capacitor values produce a slight difference in overall $N_{R f}$.

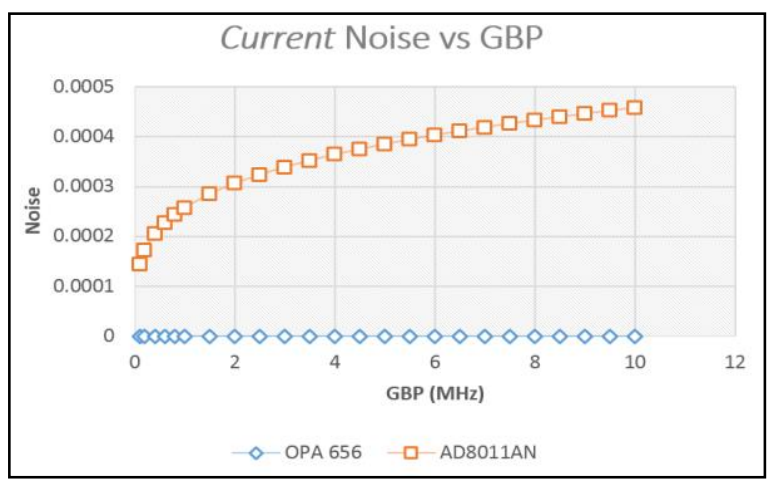

Figure 4. Graph of $N_{\text {current }}$ vs $f_{G B P}$

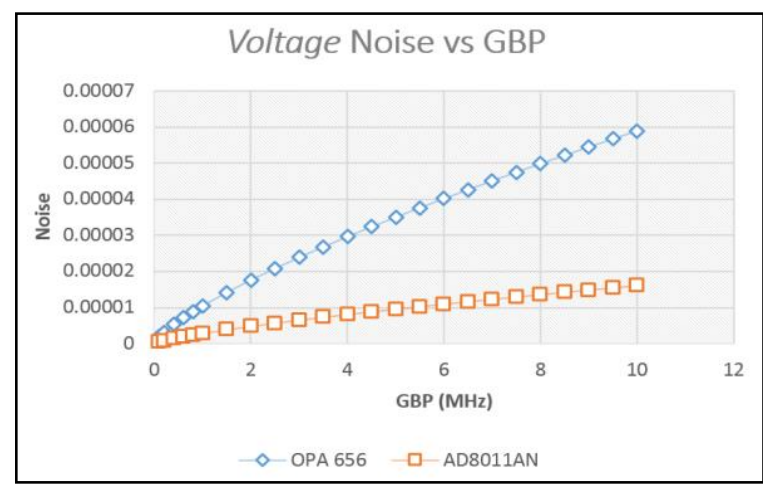

Figure 5. Graph of $N_{\text {voltage }}$ vs $f_{G B P}$

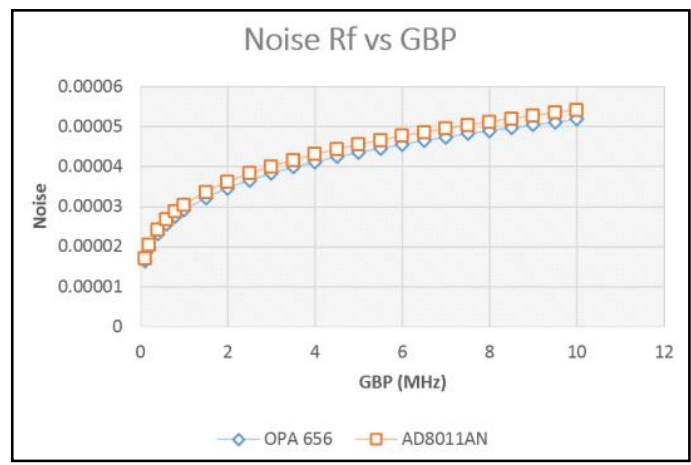

Figure 6. Graph of $N_{R f}$ vs $f_{G B P}$

In terms of the total noise $N_{\text {total, }}$, Figure 7 shows that the $N_{\text {total }}$ produced by OPA656 is lower than AD8011AN. Thanks to the huge gap on the current noise density $I_{n}$ in two Op-Amps, which contribute a 
huge gap in the total noise $N_{\text {total }}$. Hence, we can easily choose Op-Amp with the lower noise to use. It could be different if we use other kind of Op-Amp. Therefore, thorough design consideration are expected in selecting the best Op-Amp device for a particular designated VLC system.

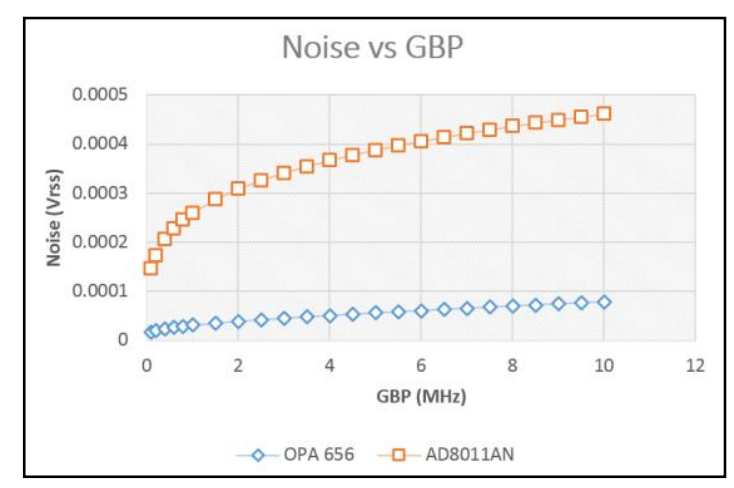

Figure 7. Graph of $N_{\text {total }}$ vs $f_{G B P}$

\section{CONCLUSION}

The idea on designing a low $N_{\text {current }}, N_{\text {voltage }}$ and $N_{R f}$ for VLC TIA are not exactly the same for all of them. In case of $N_{\text {current }}$ and $N_{R}$, the $R_{f}$ needs to be designed as low as possible and the $C_{T}$ as high as possible for obtaining low noise design. Meanwhile in case of $N_{\text {voltage }}$, both of the $R_{f}$ and $C_{T}$ need to be designed as low as possible. Therefore, a thorough design consideration are expected, because we also need to consider the selection of $R_{f}$ and $C_{T}$ depends on the operational characteristics of the Op-Amp device itself for a particular designated VLC system.

\section{NOTATIONS}

The notation used throughout the paper are stated below,

\section{Indexes:}

$N_{\text {current }} \quad$ Op-Amp input current noise [dB]

$N_{\text {voltage }} \quad$ Op-Amp input voltage noise [dB]

$N_{R_{f}} \quad$ Feedback resistor noise [dB]

$N_{\text {total }} \quad$ Total transimpedance amplifier circuit noise [dB]

$I_{n} \quad$ Op-Amp current noise density $[\mathrm{A} / \sqrt{ } \mathrm{Hz}]$

$R_{f} \quad$ Feedback resistor $[\Omega]$

ENBW Equivalent noise bandwidth [Hz]

$\mathrm{N}_{2} \quad$ Plateau noise [dB]

$f_{p} \quad$ Pole frequency [Hz]

$f_{p 2} \quad$ Second-pole frequency [Hz]

$f_{G B P} \quad$ Frequency of gain bandwidth product $[\mathrm{Hz}]$

$T \quad$ Temperature [K]

$f_{-3 d B} \quad$ Cut-off frequency or the $-3 \mathrm{~dB}$ frequency $[\mathrm{Hz}]$

$e_{n} \quad$ Voltage noise density $[\mathrm{V} / \sqrt{ } \mathrm{Hz}]$

$C_{f} \quad$ Feedback capacitance $[\mathrm{F}]$

$C_{T} \quad$ Total capacitance $[\mathrm{F}]$ 


$$
\begin{array}{ll}
C_{s h} & \text { Photodiode's shunt capacitance }[\mathrm{F}] \\
C_{i} & \text { Op-Amp input capacitance }[\mathrm{F}]
\end{array}
$$

\section{Constants:}

$k$

Boltzmann's constant $=1.38 \times 10-23[\mathrm{~J} / \mathrm{K}]$

\section{REFERENCES}

[1] Adiono T, Fuada S, and Harimurti S. Bandwidth Budget Analysis for Visible Light Communication Systems utilizing Commercially Available Components. Proc. of the 10th Int. Conf. on Electrical and Electronics Engineering. Bursa, Turkey. 2017; 1375-1380.

[2] Komine T and Nakagawa M. Fundamental analysis for visible-light communication system using LED lights. IEEE Transactions on Consumer Electronics. 2004; 50(1): 100-107.

[3] Visible light communications, The Engineer, [Online] URL: http://theengineer.co.uk/light-reading-visiblelight-communications, 2015.

[4] Pradana A, et al. Design and Implementation of Visible Light Communication System using Pulse Width Modulation. Proc. of the 5th ICEEI. Denpasar, Indonesia. 2015: 25-30.

[5] Pradana A, Fuada S, and Adiono T. Desain dan Implementasi Sistem Visible Light Communication berbasis Pulse Width Modulation. Unpublished.

[6] Adiono T, Fuada S, and Pradana A. Desain dan Realisasi Sistem Komunikasi Cahaya Tampak untuk Streaming Teks berbasis PWM. J. Setrum. 2017; 6(2): 270-279.

[7] Adiono T, Pradana A, and Fuada S. Rancang Bangun Sistem Komunikasi Cahaya Tampak dengan Modulasi 2PWM berbasis Mikrokontroller. Unpublished.

[8] Pradana A, et al. VLC physical layer design based on pulse position modulation (PPM) for stable illumination. Proc. of Int. Symp. on Intelligent Signal Processing and Communication Systems. November 2015: 368-373.

[9] Adiono T, Pradana A, and Fuada S. A Low-complexity of VLC System using BPSK. Int. J. of Recent Contributions from Engineering, Science and IT (iJES). 2018; 6(1).

[10] Adiono T, Pradana A, Fuada S, and Aska Y. Desain dan Implementasi Real-time Visible Light Communication Systems berbasis BPSK. Unpublished.

[11] Adiono T, Pradana A, and Fuada S. Visible Light Communications System using Quadrature Phase-Shift Keying. Unpublished.

[12] Adiono T, Pradana A, and Fuada S. A Low-Cost Hardware Implementation for QAM-16 Visible Light Communications. Unpublished.

[13] Fuada S. Design and Implementation of Analog Front-End Transceiver Module for Visible Light Communication System. M.T. thesis. Bandung: Dept. Elect. Eng., School of Electrical Engineering and Informatics, Institut Teknologi Bandung; 2017.

[14] Adiono T and Fuada S. Research on Analog Front-End Receiver for LiFi Systems using Commercially Available Components. Unpublished.

[15] Adiono T and Fuada S. Optical Interference Noise Filtering over Visible Light Communication System Utilizing Analog High-Pass Filter Circuit. Proc. of the 2017 Int. Symp. on Nonlinear Theory and Its Applications (NOLTA). Cancun, Mexico. December 2017: 616-619.

[16] Adiono T, Pradana A, Putra RVW, and Fuada S. Analog Filters Design in VLC Analog Front-End Receiver for Reducing Indoor Ambient Light Noise. Proc. of the IEEE Asia Pacific Conf. on Circuit and Systems (APCCAS). Jeju, South Korea. October 2016: 581-584.

[17] Adiono T, Fuada S, and Saputro RA. Automatic Gain Control Circuit for Mobility Visible Light Communication System using LM13700. Proc. of the IEEE Int. Symposium on Electronics and Smart Devices (ISESD). Yogyakarta, Indonesia. October 2017.

[18] Adiono T, Pradana A, and Fuada S. Employing LM13700 as AGC for Mobile Visible Light Communication System. Unpublished.

[19] Fuada S, Putra AP, Aska Y, and Adiono T. A First Approach to Design Mobility Function and Noise Filter in VLC System Utilizing Low-cost Analog Circuits. Int. J. of Recent Contributions from Engineering, Science, and IT (iJES). 2017; 5(2): $14-30$.

[20] Adiono T, Fuada S, Putra AP, and Aska Y. Desain Awal Analog Front-End Optical Transceiver untuk aplikasi Visible Light Communication. J. Nasional Teknik Elektro dan Teknologi Informasi (JNTETI). November 2016; 5(4): 319-327.

[21] Adiono T and Fuada S. Desain dan Implementasi LED Driver Linier untuk Aplikasi Visible Light Communication. Unpublished.

[22] Fuada S, Adiono T, Putra AP, and Aska Y. A Low-cost Analog Front-End (AFE) Transmitter Designs for OFDM Visible Light Communications. Proc. of the IEEE Int. Symposium on Electronics and Smart Devices (ISESD). Bandung, Indonesia. October 2016: 371-375.

[23] Fuada S, Adiono T, Putra AP, Aska Y. LED Driver Design for Indoor Lighting and Low-rate Data Transmission Purpose. Optik-Int. J. for Light and Electron Optics. 2018; 156: 847-856. 
[24] Adiono T and Fuada S. Prototyping Design of Low Cost Bias-T Circuit based-on Op-Amp for Visible Light Communication. Unpublished.

[25] Fuada S, Putra AP, Aska Y, and Adiono T. Trans-impedance Amplifier (TIA) Design for Visible Light Communication (VLC) using Commercially Available OP-AMP. Proc. of the 3rd Int. Conf. on Information Tech. Computer, and Electrical Engineering (ICITACEE). Semarang, Indonesia. October 2016: 31-35.

[26] Adiono T and Fuada S. Investigation of Optical Interference Noise Characteristics in Visible Light Communication System. Proc. of the 2017 Int. Symp. on Nonlinear Theory and Its Applications (NOLTA). Cancun, Mexico. December 2017: 612-615.

[27] Fuada S, Putra AP, Aska Y, and Adiono T. Noise Analysis of Trans-impedance Amplifier (TIA) in Variety Op Amp for use in Visible Light Communication (VLC) System. Int. J. of Electrical and Computer Engineering (IJECE). February 2018; Vol. 8(1): 159-171.

[28] Fuada S, Adiono T, Putra AP, and Aska Y. Noise Analysis in VLC Optical Link based Discrette OP-AMP TransImpedance Amplifier (TIA). Jurnal of TELKOMNIKA. September 2017; 15(3): 1012-1021.

[29] Fuada S, Putra AP, Aska Y, Pradana A, Setiawan E, and Adiono T. Implementasi Perangkat Digital Signal Processing untuk Sistem Komunikasi Cahaya Tampak. Jurnal Ilmiah Teknik Elektro (JETri). Februari 2018; 1(52): 101-126.

[30] Adiono T, Aska Y, Fuada S, and Purwita AA. Design of an OFDM System for VLC with a Viterbi Decoder. IEIE Transaction on Smart Processing and Computing (SPC). December 2017; 6(6): 455-465.

[31] Adiono T, Aska Y, Purwita AA, Fuada S, and Putra AP. Modeling OFDM system with Viterbi Decoder Based Visible Light Communication. Proc. of the Int. Conf. on Electronic, Information and Communication (ICEIC). Phuket, Thailand. January 2017.

[32] Putra AP, Fuada S, Aska Y, and Adiono T. System-on-Chip Architecture for High-Speed Data Acquisition in Visible Light Communication System. Proc. of the IEEE Int. Symposium on Electronics and Smart Devices (ISESD). Bandung, Indonesia. October 2016: 63-67.

[33] Adiono T, Fuada S, and Saputro RA. Rapid Development of System-on-Chip (SoC), for Network-Enabled Visible Light Communications. Int. J. of Recent Contributions from Engineering, Science and IT (iJES). 2018; 6(1).

[34] Fuada S, Putra AP, and Adiono T. Analysis of Received Power Characteristics of Commercial Photodiodes in Indoor LoS Channel Visible Light Communication. Int. J. of Advanced Computer Science and Applications (IJACSA). July 2017; 8(7): 164-172.

[35] Sharifi $\mathrm{H}$, et al. Indoor localization of mobile robot with visible light communication. Proc. of 201612 th IEEE/ASME Int. Conf. on Mechatronic and Embedded Systems and Applications. Auckland, Newzerland. August 2016: 1-6.

[36] Mare RM, et al. Visible light communication applied to intelligent transport systems: an overview. IEEE Latin America Transactions. July 2016; 14(7): 3199-3207.

[37] Cahyadi WA, et al. Patient monitoring using visible light uplink data transmission. Proc. of ISPACS. Bali, Indonesia. November 2015; 431-434.

[38] Fuada S, and Adiono T. Rancang Bangun Layer Fisik Visible Light Communication Pada Sistem Transmisi Audio. J. INFOTEL. August 2017; 9(3): 352-360.

[39] Fuada S, Putra AP, and Adiono T. Short-range Audio Transfer through 3 Watt White LED based on LOS Channels. Proc. of Int. Conf. on Intelligent Signal Processing and Communication Systems (ISPACS). Xiamen, China. November 2017: 398-403.

[40] Adiono T, Fuada S, Luthfi M, and Saputro RA. MAC Layer Design for Network-Enabled Visible Light Communication Systems Compliant with IEEE 802.15.7. EAI Endorsed Transactions on Energy Web and Information Technology. 2017; 4(14).

[41] Adiono T, Fuada S, Saputro RA, and Luthfi M. Internet Access over Visible Light. Unpublished.

[42] Fuada S. Kajian Aspek Security pada Jaringan Informasi dan Komunikasi Berbasis Visible Light Communication. J. INFOTEL. August 2017; 9(1): 108-121.

[43] Brataas PH. Wireless embedded microcontroller system for bioimpedance measurements. Master thesis. Oslo: Department of Physics, University of Oslo; June 2014.

[44] Fuada S and Adiono T. Study on Noise and Bandwidth in Operational Amplifier Based Conventional TIA for VLC. Int. J. of Recent Contributions from Engineering, Science and IT (iJES). 2018; 6(2).

[45] National Semiconductor Corporation, Design Considerations for a Transimpedance Amplifier. February 2008. 